\title{
Physicochemical Properties and Fatty Acid Composition of Castor Bean Ricinus communis L. Seed Oil
}

\author{
Orijajogun Joyce Omohu*, Ayegba Clement Omale \\ Inorganic and Material Chemistry Department, Chemistry Advanced Research Centre, Sheda Science and Technology Complex, Abuja, \\ Nigeria
}

Email address:

joycejoseph06@yahoo.com (O. J. Omohu)

${ }^{*}$ Corresponding author

To cite this article:

Orijajogun Joyce Omohu, Ayegba Clement Omale. Physicochemical Properties and Fatty Acid Composition of Castor Bean Ricinus communis L. Seed Oil. European Journal of Biophysics. Vol. 5, No. 4, 2017, pp. 62-65. doi: 10.11648/j.ejb.20170504.11

Received: August 31, 2016; Accepted: January 25, 2017; Published: November 28, 2017

\begin{abstract}
The oil content of castor seeds depends on the genotype; it is also affected by the environmental conditions, cultural practices and time of harvesting. The oil from castor bean seed obtained from Zaria in Northern Nigeria was extracted using a soxhlet method. The yield of the oil from the Castor beans is $37.8 \%$. The physicochemical properties and fatty acid composition of the seed oil of castor bean were studied. The physicochemical analysis of the oil showed iodine value 93.50 $\mathrm{mg} / \mathrm{g}$; saponification value $182.61 \mathrm{mgKOH} / \mathrm{g}$; peroxide value $5.7 \mathrm{meq} / \mathrm{kg}$; acid value $15.57 \mathrm{mgKOH} / \mathrm{g}$; free fatty acid value 7.8 and ester value $165.57 \mathrm{mgKOH} / \mathrm{g}$. The fatty acid profile showed that the ricinoleic acid comprises about $86.96 \%$ of the total fatty acid composition. The major saturated fatty acids are palmitic $(0.56 \%)$ and oleic $(5.1 \%)$. Other fatty acids present were Octanoic acid $0.29 \%$ and pentanoic acid $1.33 \%$. The castor seed oil is rich in ricinoleic acid which shows that the oil is a good source of ricinoleic acid.
\end{abstract}

Keywords: Ricinus communis, Physicochemical, Castor Bean, Ricinoleic Acid, Oil

\section{Introduction}

The castor oil plant, Ricinus communis, is a species of flowering plant in the spurge family, Euphorbiaceous. It belongs to a monotypic genus; Ricinus. Castor is an indigenous to the southeastern Mediterranean Basin, Eastern Africa and India. It is widely spread throughout the tropical regions. The castor plant is basically a tropical crop; one of its greatest virtues is that it can be grown almost anywhere.

Castor seed oil (ricinus oil, phorboyl, tangantangan oil) is a natural oil derived from the seeds of the castor bean by cold pressing for medicinal use or hot pressing for industrial purposes. Castor oil is a viscous, pale yellow, non volatile and non drying oil with a bland taste. It has good shelf life as compared to other vegetable oils. Castor seed has 37.2$60.6 \%$ oil and rich in triglycerides, mainly ricinolein a toxic alkaloid ricinine and very toxic albumen called ricin [1].

Castor seeds have a warty appendage called the caruncle, which is present usually at the end from which it runs the raphel which terminate in a slightly raised chalaza at the opposite end of the seed [2].

Castor oil is one of the few naturally occurring glycerides with high purity, since the fatty acid portion is nearly $90 \%$ of ricinoleic [3]. castor oil consists of triglyceride molecules, each containing three esters of ricinoleic acid or ricinoleates (in place of three hydroxyl groups) on a glycerol backbone. The seed of the plant contains Alkoloid ricinine and toxalbunmine ricin. The seed yields a fixed oil which has been used only for industrial and medicinal purposes [4]. Castor oil has a wide range of industrial applications: as a drying oil for paints, varnishes, plastics, and resins; in the manufacture of fatty acids; as lubricating oil. Also use in cosmetics, surface coatings, soaps and perfumes. The oil yield depends on particular seed variety, geographical origin/climatic conditions, and on the oil extraction method(s) used.

It is an excellent fertilizer due to its high nitrogen, phosphoric acid, potash contents and moisture retention capability. It also have unique properties such as its high specific gravity, thickness, and hydroxyl value [5].

The uniqueness derived from this oil is the presence of a 
hydroxyl fatty acid known as ricinoleic acid $\mathrm{C}_{18} \mathrm{H}_{34} \mathrm{O}_{3}$ (Cis 12 - hydroxyoctadeca - 9 - enoic acid), which constitutes around $90 \%$ of the total fatty acids of the oil. It is an 18 carbon hydroxylated fatty acid having one double bond [6].

India is the world's largest exporter of castor oil; other major producers being China and Brazil. [7] Had surveyed 36 castor bean varieties in Brazil for oil and fatty acid composition. A large variability of seed oil percentage was observed, ranging from $39.6 \%-59.5 \%$. Whereas [8] found out that mechanical pressing will remove about $45 \%$ of the oil present and the remaining oil in the cake can be recovered only by solvent extraction.

It was reported [9] that oil content was affected by both locations and castor oil genotypes. The seed oil content depends on the genotype but it is also affected by the environmental conditions, cultural practices and time of harvesting.

The GC - MS analysis of the essential oil from $R$. communis was reported using capillary column identified compounds like $\propto$-thujone $(31.71 \%)$ and 1,8 cineole $(30.98 \%), \propto$-pinene $(16.88 \%)$, camphor $(12.92 \%)$, camphere $(7.48 \%)$ [10].

The objective of this study is to determine the physicochemical properties and fatty acid composition of the oil extracted from Castor Bean (Ricinus communis L.) Seed Oil obtained from Zaria in northern Nigeria.

\section{Materials and Methods}

\subsection{Chemicals}

All chemicals and reagents used were of analytical grade and obtained from Sigma Chemical Company and used without further purification.

\subsection{Materials}

The castor seeds were collected from National Research Institute for Chemical Technology (NARICT), Zaria. The shells were broken and the seeds were separated from the shell. The seeds were washed and sundried. The dried seeds were then crushed using $240 \mathrm{~V} 4 \mathrm{~L}$ blender (Thomas Scientific Swedes born, U.K).

\subsection{Extraction of Castor Oil}

The seeds were picked and pulverized using an electric blender. The oil was then extracted from each of the seeds using hexane by adopting the method described by Association of Official Analytical Chemist (AOAC, 1998). $200 \mathrm{~g}$ of the pulverized seeds were packed in a muslin cloth and inserted into the soxhlet extractor and hexane was used as the extraction solvent for a period of eight hours. At the end of the extraction period, the solvent was recovered by rotary evaporator and residual oil was oven dried at $75^{\circ} \mathrm{C}$ for one hour. The extract was transferred to desiccators and then stored in air tight container until needed for further analysis. Percentage oil yield was evaluated using the expression [11]

$$
\% \text { Yield }=\frac{y_{1}-y_{2}}{y_{1}} \times 100
$$

Where $y_{1}$ is the weights of castor beans before extraction and $y_{2}$ is the weight of castor beans after extraction.

\subsection{Physico-Chemical Characteristics of the Castor Seed Oil}

The physiochemical properties of the castor bean seed oil were determined using the Institute of Public analyst of Nigeria (IPAN 2003) analytical procedure. The kinematic viscosity was determined with the Canon Ubbelohde glass tube Viscometer. The fatty acid composition of castor oil was determined by Gas Chromatography (Shimadzu GC-17A).

\subsection{Determination of Relative Percentage Fatty Acid Composition}

Preparation of fatty acid methyl ester $100 \mathrm{mg}$ of oil sample was dissolved in Petroleum ether and $0.5 \mathrm{~N}$ Sodium methoxide, with few numbers of anti- bumping granules added to the mixture. The mixture was neutralized with $0.7 \mathrm{M}$ $\mathrm{HCl}$ stirred vigorously and left on the water bath at $60^{\circ} \mathrm{C}$ for 10Mins. The fatty acid methyl ester (FAME) was separated and injected into gas chromatography powered with HP capillary column. Carrier gas $\mathrm{He}(1.6 \mathrm{ml} / \mathrm{min})$, mass spectra were taken with ionization voltage of $70 \mathrm{eV}$. Peak identification was done by comparing peak retention times with reference standards for the individual FAMEs. Retention time was defined as the time interval (min) between sample injection into the GC system and the recording of an individual peak in the chromatogram. The fatty acids were identified by comparing their retention times with those of Standard.

\section{Results and Discussions}

\subsection{Physicochemical Properties}

The physico-chemical properties of castor oil in this study are of significance because of the exceptionally high content of ricinoleic acid. The percentage yield of oil extracted from castor beans and their physicochemical properties are shown in Table 1

The oil content shows that castor seeds contain a relatively high percentage of oil: $37.8 \%$ which is in the same range as reported by [7], (35.7\%-51.9\%) for the African castor oil. [8] reported that oil content was affected by both locations and castor oil genotypes.

The castor seed oil shows a high acid value of $15.57 \mathrm{mgKOH} / \mathrm{g}$. The acid number is a measure of the extent to which the glycerides in the oil or fat have been decomposed by lipase activity or other action. [4] reported an acid value of $14.42 \mathrm{mgKOH} / \mathrm{g}$. The high acid value implies that the oil has high susceptibility to decomposition.

The oil also has high iodine value of $93.5 \mathrm{mg} /$. The iodine value indicates that the oil has high content of unsaturated fatty acid. [5] reported an iodine value of $84.5 \mathrm{mg} / \mathrm{g}$. The higher the iodine value the higher the reactivity of the oil. 
This implies that the oil is susceptible to oxidation

The saponification is useful for the detection of oil or fat with high proportion of the lower fatty acid. The oil has high saponification value of $182.6 \mathrm{mgKOH} / \mathrm{g}$. [5] reported a saponification value of $182.9 \mathrm{mgKOH} / \mathrm{g}$.

Ester value is a measure of the amount of saponifiable glyceride in the oil. The ester value was determined by substracting the acid value from the saponification value. The oil has a high ester vale of $165.57 \mathrm{mgKOH} / \mathrm{g}$.

The concentration of peroxide in the oil is a measure of the extent of spoilage. The castor seed oil has a peroxide value of $5.7 \mathrm{mEq} / \mathrm{kg}$.

The specific gravity of the castor seed oil obtained is 0.923. This value is slightly lower than the value 0.958 reported by [2]. The specific value is measure of the relative density of the oil.

\subsection{Chromatogram of the Castor Seed Oil}

The chromatogram of castor seed oil is shown in Figure 1. The fatty acids were identified by comparing their retention times with those of Standard. Table 2 shows the fatty acid composition of castor seed oil. The ricinoleic acid comprises about $86.96 \%$ of the total fatty acid composition. The major saturated fatty acids are palmitic $(0.56 \%)$ and oleic $(5.1 \%)$. Other fatty acids present were Octanoic acid $0.29 \%$, and pentanoic acid $1.33 \%$. The unsaturated fatty acids content was $86.96 \%$ of the total fatty acids composition. The ricinoleic acid content of the castor oil from Zaria Nigeria is lower than that of India and Brazil which are $94.0 \%$ and $90.2 \%$ [7] and higher than that of castor seed oil from Malaysian which is $84.2 \%$ [5].

Table 1. Physico-chemical Characteristics of the oil

\begin{tabular}{lll}
\hline Properties & & Values \\
\hline Percentage yield & $(\%)$ & 37.8 \\
Acid Value & $(\mathrm{mgKOH} / \mathrm{g})$ & 15.57 \\
Free fatty Acid & $(\%)$ & 7.8 \\
Iodine value & $(\mathrm{mg} / \mathrm{g})$ & 93.5 \\
Peroxide value & $(\mathrm{meq} / \mathrm{kg})$ & 5.7 \\
Ester Value & $(\mathrm{mgKOH} / \mathrm{g})$ & 165.57 \\
Saponification & $(\mathrm{mgKOH} / \mathrm{g})$ & 182.61 \\
Volatile matter & $(\%)$ & 6.16 \\
Specific gravity & & 0.923 \\
Colour & & Amber/pale yellow \\
\hline
\end{tabular}

Table 2. Fatty acid composition of Castor Beans Oil

\begin{tabular}{llll}
\hline Peak & $\begin{array}{l}\text { Retention Time } \\
\text { (Min) }\end{array}$ & $\begin{array}{l}\text { Relative } \\
\text { percentage }\end{array}$ & Fatty Acid \\
\hline 1 & 13.260 & 0.29 & Octanoic acid \\
3 & 18.431 & 0.56 & Palmitic acid \\
4 & 19.637 & 5.10 & Oleic acid \\
5 & 21.341 & 86.96 & Ricinoleic acid \\
6 & 22.730 & 1.33 & Pentanoic acid \\
\hline
\end{tabular}

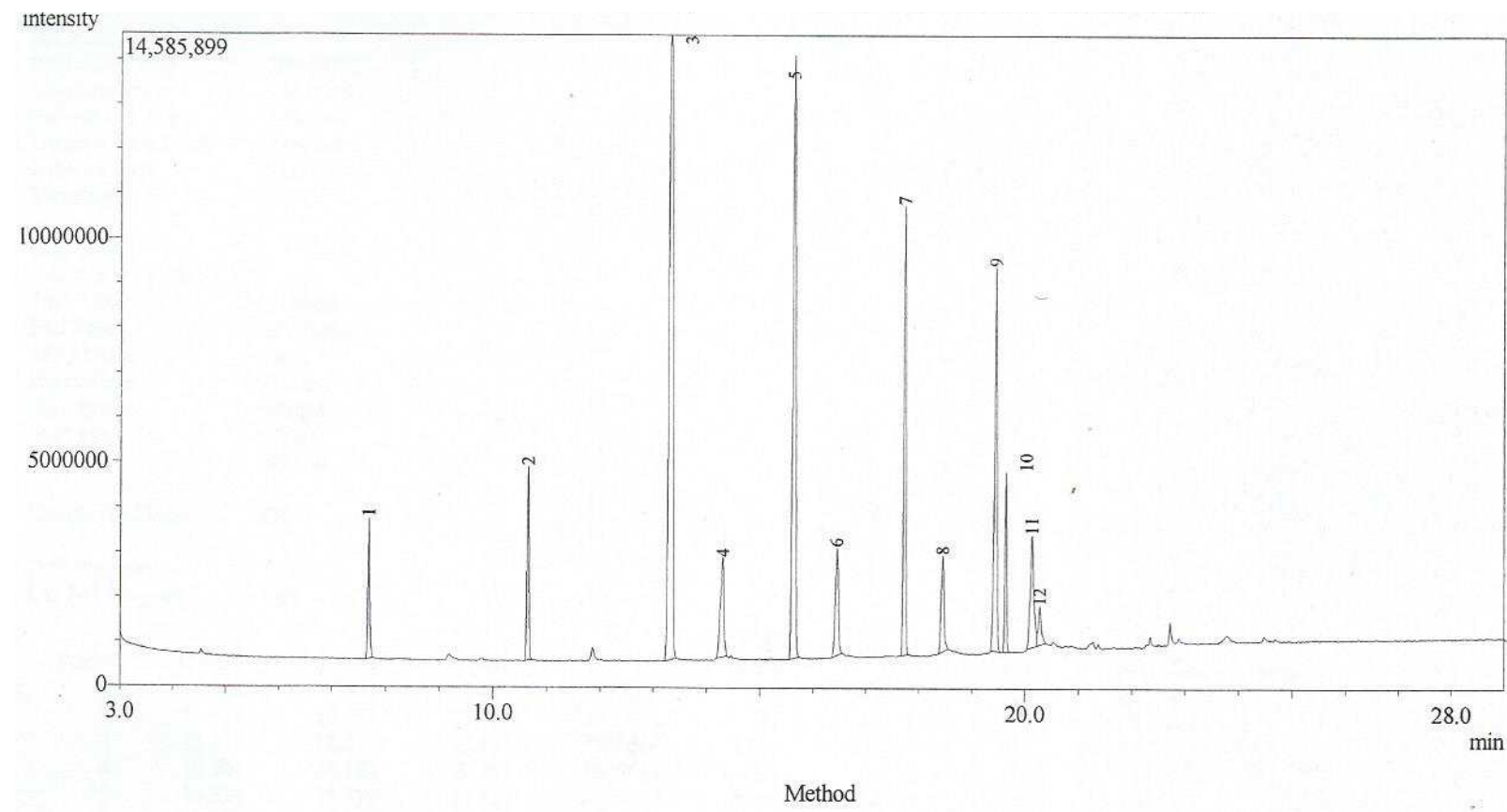

Figure 1. GC chromatogram of castor seed oil.

\section{Conclusion}

The physicochemical properties and fatty acid composition of castor seed oil from Zaria in northern Nigeria have been investigated. The extraction process gave a good yield of the oil with a yield of $37.8 \%$. The property determination of the oil showed that the oil is of good quality. The castor seed oil also shows a high content of ricinoleic acid. This implies that the oil is a good source of ricinoleic acid.

\section{Acknowledgements}

The authors are grateful to Sheda Science and Technology Complex, Abuja for facilities and support of this project. 


\section{References}

[1] Amit KJ and Amit S. Research approach and prospects of Non Edible vegetable oil as a potential Resourse for Biolubricant. Advanced Engineering and Applied sciences, 1 (1): 23-32, (2012).

[2] Trease, G. F and Evans, W. C. Pharmacognosy, $15^{\text {th }}$ Edition Saunders, (2002).

[3] Akpan UG, Jimoh A and Mohammed AD. Extraction, Characterization and Modification of castor seed oil; Leonardo journal of sciences, (8): pp 43-52, (2006).

[4] Ogunniyi DS, Castor Oil: A vital industrial raw material. Bioresource Technology, (97): 1086-1091, (2006).

[5] Adebayo TB, Rofiat TA and Victoria TB. Fatty acid composition and physicochemical properties of Castor (R. communis L.) seed obtained from Malete, Moro local Govt. Area Kwara state, Nigeria: Chemistry and material Research, (3): No 12, (2013).

[6] Jumat S, Dina AM and Nazrizawati, AT. Fatty acid composition and physicochemical properties of Malaysian castor beans Ricinus Communis L. seed oil: Sains Malaysiana. 39 (5): 761-764, (2010).

[7] Ramos, LCD, Tango, JS, Savi, A \& Leal, NR. Variability for Oil and Fatty Acid Composition in Castor bean Varieties. Journal of American Oil Chemist Society. (61): 1841-1843, (1984).

[8] Gupta, SS, Hilditch, TP and Riley, JP. The Fatty Acids and Glycerides of Castor Oil. Journal of The Science of Food and Agriculture, 2 (6): 245-251, (1951).

[9] Koutroubas, SD, Papakosta, DK and Doitsinis, A. Adaptation and yielding ability of castor plant (Ricinus communis L.) genotypes in a Mediterranean climate. European Journal of Agronomy, 11 (3-4): 227-237, (1999).

[10] Kadri Adel, Gharsallah Neji, Damak Mohammed, Gdoura Radhouane. Chemical composition and in vitro antioxidant properties of essential oil of Ricinus Communis L. Journal of Medicinal plants Research, Vol. 5 (8): 1466-1470, 2011.

[11] Muzenda, E.; Kabuba, J.; Mdletye, P. And Belaid, M. (2012): Optimization of Process Parameters for Castor Oil Production. Proceedings of the World Congress on Engineering, Vol. III, London, U.K. 